\title{
Culturally Inclusive Practice: A Case Study of an International Student Support Initiative at an Australian University
}

\author{
Jianli Wang \\ RMIT University, Melbourne, Australia \\ Tel: 61-4-3093-1145_E-mail: s3142799@student.rmit.edu.au
}

$\begin{array}{lrr}\text { Received: January 3, } 2012 & \text { Accepted: February 16, } 2012 & \text { Published: April 1, } 2012 \\ \text { doi:10.5539/ass.v8n4p68 } & \text { URL: http://dx.doi.org/10.5539/ass.v8n4p68 }\end{array}$

\begin{abstract}
This article explores from the students' as well as the coordinator's perspectives the effectiveness of an integrated culturally inclusive initiative in terms of facilitating international students' adaptation. This initiative is a program that celebrates international students' diverse learning cultures through sharing and understanding different cultural ways of learning. This study builds upon the extensive research conducted focusing on international students' adaptation processes with a case-study approach consisting of participant observation, document analysis, questionnaire and in-depth interviewing. My findings support this initiative as a successful program providing support for international students. It is an effective practice for students, educators and policy makers in wider fields where intercultural dialogues are cherished.
\end{abstract}

Keywords: Relaxation, Confidence, Support, Cultural inclusion

\section{Introduction}

International students form a large proportion of the overall student body in Australia and they come from diverse regions as well, which contributes to the cultural diversity of Australian student education. This is reflected in growing research and study interest in investigating international students' well-being (Batorowicz, 1999; R. Burns, 1991; Furnham, 1997; Germov \& Williams, 2001; Halic, Greenberg, \& Paulus, 2009). Concurrently, many international students' destination countries like Australia are endeavoring to attract more. This is echoed in almost all stakeholder statements involved with international education in the areas of government policies, media, university supporting facilities, and existing and growing numbers of study and research interests concerning international students (Bull, 1996; Gillard, 2008; Wee \& Edwards, 2006; Zadkovich, 2010).

To date, whilst a large number of research studies have been conducted in relation to international education in Australia, most research studies focus mainly on student language issues and cultural differences (Benzie, 2010; May \& Bartlett, 1995; Mitsis \& Foley, 2009; Strang, 2010). Too often, "international students have been seen only from a "deficit" frame", which tends to "locate international students' challenges as emerging exclusively from their cultural backgrounds" and thus "their different ways of constructing knowledge are considered as problematic" (Tran, 2011, p. 81).

Emergent themes in literature appear in the areas of cultural learning styles (Eisenchlas \& Trevaskes, 2007; Marlina, 2009; Parekh, 2006; Singh \& Han, 2009) and Asian students' learning experiences (Crossman \& Clarke, 2010; Russell, Rosenthal, \& Thomson, 2010; Tran, 2010). Highlighted in these studies is the need for initiatives set up to support international students' adaptation processes.

This study attempts to contribute to this growing area of knowledge. It argues that international students bring complex learning beliefs with them into their programs in Australia. Building upon the findings of the literature, this research aims to explore the effectiveness of this initiative in terms of helping international students' adaptation to Australian teaching and learning community.

\section{Background}

The existence of international students has enriched cultural diversity for the Australian student cohort. As more international students choose Australia to study, governments and educators have been trying to find ways to manage cultural pluralism. Australia "officially declared itself multicultural and committed itself to 
multiculturalism in the early 1970s" (Parekh, 2006, p. 5). Afterwards, the Australian government has made changes to laws that cover international students who are studying in Australia, which give students more flexibility in their study options. The Australian government values the significant benefits from its export of education and training services. As Department of Education and Science and Training (Department of Education, and Science, \& and Training, 2007) claims

Australia gains significant benefits from its export of education and training services. The social and economic benefits flow to individuals, institutions and the wider community. .... International engagement in education and training can transform individuals, widening the intellectual horizons, opening them to new ideas and experiences, and extending their friendships. International students also contribute intellectually to Australian education and society, and provide diverse social and cultural perspectives that enrich the educational experience for many Australian students (p. 3).

Although Australia gains many benefits from international students, "the benefits of international education and training depend on the service provided to international students, on public confidence in the integrity and quality of that service" (DEST, 2007, p. 3) as well as on institutions' awareness of the diverse cultural backgrounds embedded in international students.

The University within which this study had taken place is a culturally diverse institute, striving to respond to and meet the government's standards of providing services to international students as well as achieving the goal of culturally inclusive practice, which Sebba and Sachdev (1997) maintain "reflect[s] the value of diversity, not the assimilation or tolerance of differences" (p. 10). This is aligned with the current preferred philosophy of valuing cultural diversity and nurturing inclusive practices.

Not only is the number of international students at this institute large, but those international students also come from diverse cultural backgrounds. There is vast student and staff diversity in cultures, life experience, education, knowledge, skills and expertise, as well as values, beliefs and attitudes. In responding to this diversity, this university developed its code of ethics: "we respect diversity within humanity including gender, spiritual values, sexual preference, age, disability and culture and provide services to support this" (RMIT University, 2005, p. $3)$.

Based upon the recognition of cultural diversity, in response to its institute's Code of Ethics as well as to provide assistance to international students to better adapt to their academic and learning community, a one-year long initiative was timely set up from the School of Education. This initiative purports to value international students' cultural diversity and to offer social, cultural as well as academic support so as to assist international students to better adapt to their academic studies in the larger university learning community. Participants in this program are volunteers from different cultural backgrounds and this diversity was cherished in this initiative to facilitate international students' feeling of value and inclusion.

International students experience a wide range of difficulties while studying in Australia, largely based around a clash of educational cultures, or attitudes toward knowledge and toward teaching and learning styles. These difficulties derive from cultural differences (Ballard \& Clanchy, 1997), which signify a necessity for universities to offer opportunities for international students as well as staff to further their understandings of cultural differences on learning.

\section{Methodology}

\subsection{Case Study}

This study was bounded by the location of this institute, by time of a one-year period, and by timeline of the initiative, and as such, was a bounded system which fitted well in a case study design. Case studies are used to gain in-depth understanding of a particular topic or phenomena. Unlike other research methodologies, the focus is more on what is gleaned from the process than the end result. In case studies, the researcher often collects extensive qualitative data to gain a deeper understanding of the entity being studied; therefore, the case study approach allows an investigation to retain the holistic and meaningful characteristics of real life events (R. B. Burns, 2000). This study involved the collection of qualitative data to provide detailed and holistic description of the case in order to effectively understand how it operated or functioned. Questions this study expected to explore sat around the structure of this initiative, the philosophies that underpinned it and how effective the program was, in terms of helping international students feel included in a community of practice.

\subsection{Goals and Participation Objectives of the World Education Initiative}

This initiative was a multi-cultural study and social group in the School of Education organized by Dr Jane Rivers (Note 1), an international student coordinator, who called it World Education. This program's goals were helping international students to 
- Gain skills to teach in a multicultural school setting

- Learn more about Australian schools

- Recognize different learning styles among people from diverse countries

- Get to know students from other cultures and form friendships

- Gain recognition of leadership through a LEAD certificate from the university after reaching the requirements of the program.

International students and local students could participate. The idea was that each student worked with another student from a culturally different background on a pair basis. Included in the program activities were shared understandings of

- Each other's school experiences

- Each other's beliefs about teaching

- Each other's beliefs about learning

- How their parents view education

- Ideas about how to prepare for and work on assignments

- What's important at university from different perspectives

- Experiences and what each other learned at school placements

- Ideas about key points of papers and articles

- Strategies for getting help at university

- Ideas about their learning strategies

- Songs in multiple languages

For the LEAD certificate, students needed to have five hours training in multicultural education with the coordinator. During those five hours, they watched a video about Australian schools and they also viewed a video of a multicultural school. Apart from these, they also looked at different learning and reasoning styles, an exploration which was intended to nourish students' cultural awareness. After these five hours cultivation of multicultural education, students were put into pairs. They could choose whom they worked with (but they must be from different countries), or the coordinator could organize the students if they preferred. Students got three weeks to explore each other's cultures focusing on differences in family structures, friendships, schooling and university after they were put into pairs. They also had a room to meet each other weekly (if they wanted to) to talk and share ideas. They then got together in groups and presented to the whole group about what they had learned about their partners' different cultural ways of learning. This time was counted as part of the 15 voluntary hours to receive a leadership certificate from the University and, as Dr Rivers put it, "actually, students usually do more than the required hours". In addition, they also shared their academic challenges and other social events, which were focused upon during the second semester. At the start of the second semester, participants were encouraged to provide ideas about what they wanted from this program. Richard suggested a football match, Josef thought having a barbeque might be a good idea, Chen Min wanted to learn some Australian songs, Du Wen invited students to the Chinese moon festival, and so forth, which were written down and supported by the coordinator. Participants might also be asked to do presentations on multicultural education to staff and to other students.

\subsection{Philosophies Underpinning the Organization of This Initiative}

Dr Rivers explained in the interview that the philosophy behind the idea of providing support to international students was not one of remediation, nor was it one based upon stereotypes of international students from other cultural backgrounds as somehow less capable than their peers from Australia. Rather, the foundation of this initiative was built upon the recognition of the complexities of entering the Australian educational context, with different academic and learning backgrounds.

There were two basic assumptions underpinning this initiative, according to Dr Rivers, one being commonality and the other being trust. Dr Rivers further explained she applied Nel Noddings' (1984) concept of ethics of care and Annette Baier's (1994) concept of trust and how trust comes through the development of friendship as the basis of the program. Apart from this, interaction and communication between students were advocated by the coordinator as well. 
In the light of the preferred philosophy of culturally inclusive practice, Sebba and Sachdev's (1997) claim is "to reflect the value of diversity, not the assimilation or tolerance of differences" (p.10). Dr Rivers strove to value every student's culture through song, story, food, social and educational systems, as she believed valuing cultural diversity creates opportunities for students to "enlarge their cultural repertoire of strategies". In this diverse cultural community, everybody learns (Cortazzi \& Jin, 1997, p. 89).

Dr Rivers also reported using Lave and Wenger's (1991) concept of communities of practice, as communities of practice "foster belonging by embracing its members" (Lesser, Fontaine, \& Slusher, 2000, p. 14), which was the primary purpose of this initiative. This program was also an initiative that responded to its University's code of ethics to value cultural diversity and help international students feel connected.

\subsection{Selection of Participants}

This supportive program was initiated to provide assistance to international students at one Australian University in the year 2006. Dr Rivers was assigned as the coordinator. Her own personal experiences of living overseas and experience of culture shock and language problems had inspired her organization of this program. Dr Rivers also had Asian friends when she was young, which provoked her interests in Asian cultures. As a coordinator who looked after international students, Dr. Rivers believed this would be something interesting and rewarding. As well, she thought she could do the job reasonably well because of her personal experiences and her concerns about international students. Dr Jane Rivers believed "loneliness is a dreadful feeling", thus she intended to help international students feel less lonely through organizing this initiative. Furthermore, she also wanted students to learn more quickly about Australia, which she hoped might bring more confidence to them. Apart from this, Dr Rivers also wanted staff to understand cultural differences, as she claimed that "not all teachers know problems international students experience from cultural mismatching". Therefore, she hoped, "this might bring cultural awareness to more teaching staff, consequently encouraging a flow-on effect for teachers".

Participants in this research comprised the coordinator and students participating in this program. Around twenty students who enrolled in this program were invited to complete a questionnaire. Based on their responses, ten were chosen for interviewing: four Chinese (there were approximately seven Chinese students), one Indian (three students coming from India), one Korean (one student coming from Korea), two coming from English speaking countries, but they were still international students; and two Australian students. This selection was based on a small but representative sample of participants in this program.

\subsection{Data Collection}

Flyers and documents inviting students' participation were collected at first to gain general information about this initiative. This information included how the coordinator viewed her program and what her perspectives were. From this perspective, this document analysis would be "a passport to listening to the words of the text and understanding better the perspectives of the producer of these words" (Berg, 2007, p. 308).

A questionnaire was handed out to participants near the end of this program to gain participants' perspectives about the effectiveness of this initiative. The reason for employing questionnaires in this research was that questionnaires can "elicit information from a respondent that covers a long period of time in a few minutes, and it could also go beyond description to looking for patterns in data" (R. B. Burns, 2000, p. 567). The questionnaire in this research consisted of eight closed questions and eight open-ended ones. Among those closed questions, there were questions relating to gender, age, nationality, time since first arrival in Australia, and whether English is the first language or second language. These questions provided demographic data as the background information influencing the participants' communication, behavior, values and beliefs. There were also open-ended questions around general issues about this initiative in this questionnaire, as "open-ended questions are flexible and therefore, facilitate a richness and intensity of response" (R. B. Burns, 2000, p. 572). These open-ended questions focused on questions that explored participants' initial experiences before participation of this program, experiences after participation of this program and their evaluation on the effectiveness of this initiative in terms of assisting them feel included, valued, and with their academic study. The questionnaire in this research was helpful to provide basic snapshot information to address the research questions raised in this inquiry, as well as provided a basis for follow-up semi-structured interviews to probe further detailed and holistic data from the participants.

The qualitative data collected from the questionnaire was then supplemented by a number of semi-structured interviews. Stake claims, "qualitative researchers take pride in discovering and portraying the multiple views of the case" and "interview is the main road to multiple realities" (1995, p. 64). Semi-structured in-depth interviewing, according to Taylor and Bogdan (1984) offers "repeated face-to-face encounters between the researcher and informants directed toward understanding informants' perspectives on their lives, experiences or 
situations as expressed in their own words" (p. 77). This definition highlights understanding participants' perspectives, which is the primary purpose of conducting this research on the value of a supportive structure to international students' lives. The interviews were audio-recorded for further analysis. Both students as well as the coordinator were individually face-to-face interviewed once near the end of this program to provide multiple viewpoints. These interviews lasted around 30 minutes located in a group study room in the library. Participants' perspectives about their initial experiences of studying in Australia, their experiences in the World Education initiative and their evaluations on the effectiveness of this program were explored in the interviews.

\subsection{Data Analysis}

Data collected was initially organized into categories on the bases of themes, concepts or similar features, which mainly come from two sources, which as Patton (1987) claims are (1)...questions that are generated during the conceptual design phases of the project and (2) analytical insights and interpretations that emerge during data collection" (p. 144). Those categories were further assisted by themes from the literature and terms used by participants.

Through comparing international students' reports of their experiences before and after participation in this program, the effectiveness, in terms of helping them feel included emerged. During the second phase of analyzing data, instead of focusing on the initial themes, the responses that the participants provided were focused, aiming to identify new themes or concepts by repeated studying of the data. The information contained within the participants' responses was then further refined by streaming the data into different themes under the research questions.

Literature was constantly reviewed to form theoretical frameworks and to facilitate the organization of data during the analytical and reporting stages. Further triangulation was provided by prolonged observation and member checking.

\section{Students' Experiences in This Program}

The findings of this study related to the themes explored students' initial experiences at the university, their experiences in the World Education initiative and their evaluations on this program. The main themes addressed were support, cultural inclusion, confidence and relaxation.

\subsection{Initial Experiences}

Participants' initial experiences of studying in the Australian university were explored as a basis to evaluate the effectiveness of this initiative. All participants even those from English-speaking backgrounds claimed that they had experienced culture shock to some extent, those international students whose home culture of being different from their host culture claimed they experienced cultural exclusion and expectation mismatch in their Australian classrooms. This mismatch led to frustration, which caused unpleasantness to their learning processes. Some students felt either excluded (Wang Jian) or isolated (Zoe). As a consequence, some of them even wanted to escape because they felt they were not included.

Even though language is a big barrier for international students' whose first language is not English to participate and being included in the learning community, cultural influences on learning can cause misunderstanding and frustration. From an intercultural communication perspective, "both teachers and students are likely to experience uncertainty and anxiety when they are unable to adequately predict each other's behaviour, expectations, and norms for success" (Garcia \& Guerra, 2006, p. 104). Students talked about different writing and reasoning styles in one of the early sessions in the initiative. Moreover, many students thought the training was very helpful as they had gained some knowledge about different writing styles and therefore, they could better cope with their study at University.

\subsection{Experiences in the World Education Initiative}

Most participants in this program were international students, because of which, they felt more comfortable interacting with each other. Zhang Fei argued because most international students in this program spoke English as their second language, she felt more confident expressing her opinions, and she felt "in the class, even though I make mistakes, they will not laugh at me because we come from the same background". However, without this common sharing, the experience might be a little bit different. An Mou claimed her feelings in one of her courses,

All the students already know the background knowledge about that course, and they already know the lecturer and they are already familiar with the subject. But those are all new to me. Besides all the students are Australian, not from Asia at all. So I felt really scared in the class. 
Garcia and Guerra (2006) researched multicultural education finding "those who increased their cultural knowledge and skills were then able to recognize the influence of their own cultural values and those in the school culture on academic outcomes for many of their low-performing students" (p. 110). Exposure to students coming from other cultures helped students look into themselves. May, who was Australian but lived in Japan for 3 years felt that it was weird when she went back to classrooms in Australia again, because she was not the foreigner any more, but exposure to diverse cultures helped her to reflect on herself and she thought she always looked out, so sometimes she forgot to look into herself. Exposure to diverse cultures not only helped students look into themselves, it also cultivated students' cultural awareness. An Mou asserted there were not many international students in Korea, not many students coming from diverse cultural backgrounds, and she did not have any idea about multicultural schools. But when she watched the videos about multicultural education, she claimed, "oh, my god, it was another world, I was really amused. I did not think about that kind of classroom. .... And that meeting is very helpful for all to understand multicultural education".

Most students' experiences were valued and became the central part of this program. Their cultural differences were also valued and discussed in this program. This initiative on another level also helped students to socialize with each other. Because of more understanding of students coming from other cultures, Zoe felt she can mingle with others according to their interests. She commented, "if a Chinese person came, I know she is Chinese and I will go according to their cultures, and thus, I can move toward friendship with them". Apart from those mentioned above, there were four themes came from close scrutiny of the data collected.

\subsubsection{Support}

If students have their family members here in Australia with them, they will be less affected by loneliness and feel they have an anchor here. However, it was quite different for those who do not have that kind of support with them. Jim had his partner here with him, but he imagined that "if you do not have that support, then you tend to rely on the people around you .... We are here and may not have that support network. I think this program is really valuable to people who are in that situation".

Not only did this program provide emotional support, it also provided opportunities for students to socialize with each other. Josef called it "the wax" and he commented, "it is good for everybody; it is the gate into the conversation". Also because of its relaxed nature, Richard felt no pressure while being part of this program.

Although Du Wen and Wang Jian felt this program was effective in terms of providing support, Zoe, Zhang Fei and May disagreed with other students. Zoe did not think it was supportive due to "some of the students used to maintain distance". However, Zhang Fei and May regarded interaction as the cause for not being a supportive community. Zhang Fei felt they did not have enough time to communicate, whilst May asserted, "there are quite a few people that I have not spoken to in the class, actually quite a lot of people, which I think a little bit weird".

\subsubsection{Cultural Inclusion}

In workshops, students usually talked about their cultural differences, which did not necessarily mean their differences are valued. However, students felt they belonged here because of sharing their differences. An Mou said

In the workshops, it is really talk about our differences, we talk about ourselves, exchange our cultures. So the others are really interested in my culture and I really interested in their cultures, so we made really good conversations. Yes, it was really good.

Zoe argued, "on the whole, we gained some information about some countries, which helped us feel confident and at the same time; value one's own cultural background". Students' cultural backgrounds were not only valued through interaction, they were also valued through food and languages. For instance, in one of the workshops, students sang songs, not only in English, but also in Chinese and Indian. All students kept clapping their hands as well as laughing. Josef reflected that when students heard somebody say goodbye or hello in their own languages, they felt very good and they claimed they were part of the community. He thought "this program is pretty inclusive. I do not feel nervous or excluded or anything. It is probably as inclusive as you can get really, [...]. The food, it is also very inclusive." But he thought some of the Australians might feel a little bit nervous about coming, because "I am an Australian, I am not an international student, so I might feel a little bit nervous and I might feel a little bit excluded". This might be why May felt "weird" in the workshops, as "she is not the foreigner any more". However, Richard declared this program was very inclusive, and claimed the coordinator's personality also contributed to this inclusiveness. Richard surmised that "the coordinator is very nurturing and she just has a very lovely nature, which embraces everyone, open to everyone and non-judgmental. I think that is good for everyone".

\subsubsection{Confidence}

This initiative helped international students build up their confidence in a number of ways. Zhang Fei thought the coordinator helped her to speak up confidently. She thought of herself as a person who if others do not force her to say something, will not do it. But sometimes in the workshops, 
"the coordinator nominates somebody to say something. [...]. So I have to open my mouth and say something. I think that gives me more experience to speak publicly, so it gives me confidence".

Wang Jian also argued the structure of this program itself helped her a lot. Because they were participants in this program, they all had similar goals, which were to learn about other cultures. Meanwhile, each student was a learner as well as a provider. Therefore, Wang Jian declared, they had more in common, and "we understand each other better, and know that most of them are second language speakers, which by itself gives me more confidence". Moreover, some other students built up their confidence through the process itself. Cheng Min was a shy girl and she always found it hard to speak up to native speakers because she had no confidence to stand up and speak English to them. Although she did not explicitly claim this initiative helped her with her confidence, she appeared to be more confident this semester than last semester. She tended to speak quite a lot in the meetings. Not only did she talk directly with Josef and Jim whenever she got a chance, more than twice she was also the first to speak up and sang Chinese songs in the presence of other students.

Not only did international students feel confident in the workshops of this program, local students also benefited from this. Richard reckoned "in a number of ways, yes, this program does make me feel confident". Although most students thought it was effective in helping them build up their confidence, Du Wen thought she "is already confident enough".

\subsubsection{Relaxation}

Josef claimed

You can get nervous sitting around in a circle, you are American, Jim is Scottish, or Zhang Fei comes from China, and you can feel like you represent China to these people. People can get the wrong idea. Some people would meet two Chinese people or two Americans and think that is what all Americans are like.

Generalized thinking is unavoidable; however, interaction and understanding can help people recognize individuality. Dr Rivers calls this initiative a "culture club", because it was informal, and because of this informal nature, students felt more relaxed. Participants were encouraged to bring food to this club, so they could communicate and learn each other's cultures while eating, which also inspired other elements of relaxation. Students always moved around during the meetings whenever they liked. Although An Mou and Zoe always appeared to be serious, Du Wen and Zhang Fei seemed to be very comfortable and they laughed a lot as well. Josef usually crossed his legs and kept clapping the desk when he sang songs, and Jim sometimes tapped his fingers on the desk to accompany Josef, while some other students also put their arms around their peers and laughed with them. Furthermore, "it is not like you chat with a TV, you are actually learning but in a more informal environment" (Jim). Josef from America claimed

It is good when it is relaxed, and I just think even interaction is good. [...]. I think you could probably take it more seriously, may get more out of it, but it may feel more like a class. But I think because it is relaxed, more people come, maybe people would not share much when it was too serious. Maybe I get more out of it because it is relaxed. I think relaxed is the way to go. It is good and it is very open-ended.

However, Du Wen did not think she learned much from this relaxed situation and she thinks "sitting and relaxing are not really meaningful. [...]. I do not think there are lots who really treat it seriously".

Perhaps Du Wen's view was influenced by her Chinese educational culture. However, this might also relate to personal attributes. Although Cheng Min and Wang Jian come from China, they felt relaxed and they thought they had learned quite a lot. Cheng Min felt relaxed because "we are always eating while we are talking" and Zoe asserted she was a positive person and she thought about all this positively, "So it helps a lot. Positive attitude is very important for a person". On the other hand, May did not think relaxed was the way for her, because she was busy, so she did not allow this program to let her sit and feel relaxed this year. She did not think she would apply the word 'relaxed' to her.

\subsection{Evaluations on World Education Initiative}

Overall, World Education stands as a successful culturally inclusive initiative. Among the study's findings, the participants, as well as the coordinator perceived that this initiative was successful as a culturally inclusive practice, particularly in promoting confidence, support, and a sense of belonging. This study found that the group discussion worked well as it stimulated interaction about different cultural ways of learning. As a result, most participants of this program felt included in the sense that they were more confident to talk and engage, felt valued in the sense that their cultural backgrounds were being shared and understood, felt supported in the sense that this initiative acted as a social network, and felt connected in the sense that this initiative provided help and assistance for their academic adaptation with a relaxing atmosphere. The findings of this study expanded the literature in the sense that international students' different ways of constructing knowledge rather than being regarded as problematic and needing to be corrected, illustrated an acknowledgement and showed value of their different cultural ways of 
learning preferences, which also recognized the benefits that international students could bring to our multi cultural classrooms in Australia.

\section{Conclusion}

My findings illustrated some of the comments and claims made in the literature, just as Garcia and Guerra (2006) found that if educators increase their knowledge of cultural awareness, they can better recognize their own cultural influences on their values and those of their students as well. It also extended the literature in the sense that it provided valuable information for educators and policy makers on operation of such initiatives. As discussed above, there is considerable evidence to show that the initiative stands as a successful culturally inclusive practice in terms of helping international students feel valued and included.

When international students first arrive in Australia, they experience culture shock and study challenges to various degrees. Dr Rivers had set this program up, not to 'bring them up to speed', but to celebrate international students' diverse cultures through story, song, food, social and educational systems and so forth, which positioned international students quite positively. It helped students, especially international students to build up confidence and a social network, as well as strongly encouraging a sense of inclusion.

This initiative also provided educators with information about international students' various cultural perceptions as well as supported them with understanding and knowledge of culturally inclusive practices. My findings suggest that lecturers and tutors and other educators with classes of international students might assist international students' academic adaptation through organizing groups of mixed cultural backgrounds, foregrounding their own cultural preferences over learning, as well as recognizing international students' differences in learning preferences. My findings also suggest that universities as well as different schools need to embrace and support initiatives like the present one that value international students' different learning experiences because this can provide support for international students' adaptation processes.

My findings also suggest that international students regard the acceptance of their local peers and constructing mutual friendships with them as being of importance for their adaptation. I believe that future research into the areas of local students' perspectives on constructing mutual friendships with international students to better improve international students' sense of belonging needs to be carried out on this front. Furthermore, further research might be needed to see if the findings of this study can be replicated in larger populations and whether findings might apply to other international student contexts.

\section{References}

Baier, A. (1994). Moral Prejudices: essays on ethics. Cambridge, Massachusetts, and London: Harvard University Press.

Ballard, B., \& Clanchy, J. (1997). Teaching international students: a brief guide for lecturers and supervisors. Deakin, A.C.T.: IDP Education Australia.

Batorowicz, K. (1999). A fair go? The problems and needs of international and non-English speaking background students at Australian universities. Youth Studies Australia, 18(3), 37-40.

Benzie, H. J. (2010). Graduating as a "Native Speaker": International Students and English Language Proficiency in Higher Education. Higher education research and development, 29(4), 447-459. http://dx.doi.org/10.1080/07294361003598824

Berg, B. L. (2007). Qualitative research methods for the social sciences (6 ed.). Boston: Allyn and Bacon.

Bull, I. M. (1996). Faculty exchanges and the internationalization of undergraduate curricula in Australia and the United States. Unpublished 9703774, The University of Nebraska - Lincoln, United States -- Nebraska.

Burns, R. (1991). Study and stress among first year international students in an Australian university. Higher education research and development, 10(1), 61-77. http://dx.doi.org/10.1080/0729436910100106

Burns, R. B. (2000). Introduction to research methods (4 ed.). Sydney: Pearson Education Australia.

Cortazzi, M., \& Jin, L. (1997). Learning across cultures. In D. McNamara \& R. Harris (Eds.), International students in higher education: issues in teaching and learning. London and New York: Routledge.

Crossman, J. E., \& Clarke, M. (2010). International experience and graduate employability: stakeholder perceptions on the connection. Higher Education, 59(5), 599. 0018-1560. http://dx.doi.org/10.1007/s10734-009-9268-z

Department of Education, and Science, \& and Training. (2007). The national code 2007. Retrieved August 4, 2007, from http://www.rmit.edu.au/international/nationalcode2007

Eisenchlas, S., \& Trevaskes, S. (2007). Developing Intercultural Communication Skills through Intergroup Interaction. Intercultural Education, 18(5), 413-425. 1467-5986. http://dx.doi.org/10.1080/14675980701685271 
Furnham, A. (1997). Being an overseas student. In D. McNamara \& R. Harris (Eds.), International students in higher education: issues in teaching and learning. London; New York: Routledge.

Garcia, S. B., \& Guerra, P. L. (2006). Conceptualizing Culture in Education: Implications for Schooling in a Culturally Diverse Society. In J. R. Baldwin, S. L. Faulkner, M. L. Hecht \& S. L. Lindsley (Eds.), Redefining culture: perspectives across the disciplines (pp. 103-115). New Jersey: Lawrence Erlbaum Associates, Inc.

Germov, J., \& Williams, L. (2001). Surviving first Year University. N.S.W.: Allen \& Unwin.

Gillard, J. (Producer). (2008) Leading 21st Century Schools Engage With Asia Forum. Retrieved January 2, 2008, from: http://www.deewr.gov.au/ministers/gillard/media/speeches/pages/article_081009_114323.aspx

Halic, O., Greenberg, K., \& Paulus, T. (2009). Language and academic identity: a study of the experiences of non-native English speaking international students. International Education, 38(2), 73.

Lave, J., \& Wenger, E. (1991). Situated learning: legitimate peripheral participation. Cambridge: Cambridge University Press.

Lesser, E. L., Fontaine, M. A., \& Slusher, J. A. (2000). Knowledge and communities. Boston: Butterworth-Heinemann.

Marlina, R. (2009). "I Don't Talk or I Decide Not to Talk? Is It My Culture?"--International Students' Experiences of Tutorial Participation. International Journal of Educational Research, 48(4), 235-244. 08830355. http://dx.doi.org/10.1016/j.ijer.2009.11.001

May, M., \& Bartlett, A. (1995). "They've Got a Problem with English": Perceptions of the Difficulties of International Post-Graduate Students. Report: ED420202. 13pp. 1995.

Mitsis, A., \& Foley, P. W. (2009). Do Business Students' Culturally Anchored Values Shape Student-Driven or Teacher-Driven Learning Style Preferences? Journal of Marketing Education, 31(3), 240-252. 0273-4753. http://dx.doi.org/10.1177/0273475309345000

Noddings, N. (1984). Caring, a feminine approach to ethics and moral education. Berkeley: University of California Press.

Parekh, B. C. (2006). Rethinking multiculturalism: cultural diversity and political theory (2nd ed.). New York: Palgrave Macmillan.

Patton, M. (1987). How to use qualitative methods in evaluation. London: Sage Publications, Inc.

RMIT University. (2005). Human Resources Policies and Procedures Manual Code of Ethics.

Russell, J., Rosenthal, D., \& Thomson, G. (2010). The international student experience: three styles of adaptation. Higher Education, 60(2), 235. http://dx.doi.org/10.1007/s10734-009-9297-7

Sebba, J., \& Sachdev, D. (1997). What works in inclusive education? Ilford: Barkingside, Barnardo's.

Singh, M., \& Han, J. (2009). Engaging Chinese Ideas through Australian Education Research: Using "Chengyu" to Connect Intellectual Projects across "Peripheral" Nations. Discourse: Studies in the Cultural Politics of Education, 30(4), 397-411. http://dx.doi.org/10.1080/01596300903237180

Stake, R. E. (1995). The art of case study research. California;Thousand Oaks: Sage Publications Inc.

Strang, K. D. (2010). Improving Supervision of Cross-Cultural Postgraduate University Students. International Journal of Learning and Change, 4(2), 181-202. 1740-2875. http://dx.doi.org/10.1504/IJLC.2010.032711

Taylor, S., \& Bogdan, R. (1984). Introduction to qualitative research methods. New York: Wiley.

Tran, L. T. (2010). Embracing prior professional experience in meaning making: views from international students and academics. Educational Review, 62(2), 157. http://dx.doi.org/10.1080/00131910903548669

Tran, L. T. (2011). Committed, Face-Value, Hybrid or Mutual Adaptation? The Experiences of International Students in Australian Higher Education. Educational Review, 63(1), 79-94. http://dx.doi.org/10.1080/00131911.2010.510905

Wee, S., \& Edwards, J. (2006). Flying in, flying out: Offshore teaching in higher education. Australian Journal of Education, 50(3), 297.

Zadkovich, G. (2010). Seeing through Gillard's agenda. Education, p. 5. Retrieved January 9, 2010, from http://proquest.umi.com/pqdweb?did=2039239241\&Fmt=7\&clientId=16532\&RQT=309\&VName=PQD

\section{Note}

Note 1. All names used in this article are pseudonyms to protect the identity of the participants. 